\title{
The effects of stimulus preexposure on taste-mediated environmental conditioning: Potentiation and overshadowing
}

\author{
MICHAEL R. BEST and CYNTHIA L. MEACHUM \\ Southern Methodist University, Dallas, Texas
}

\begin{abstract}
On four occasions, Holtzman rats drank saccharin in a distinctive environment prior to lithiuminduced toxicosis. Preconditioning exposure to saccharin either in the home cage or in the distinctive environment interfered significantly with the establishment of an environmental aversion. Animals preexposed to the experimental environment, however, showed environmental aversions substantially stronger than those in animals preexposed to saccharin and only slightly higher than those with no preexposure to either the taste or the environment. Subsequent saccharin tests revealed significantly stronger aversions in the group that received environmental preexposure than in any of the other groups. This pattern of outcomes demonstrates taste-mediated potentiation of novel and familiar environmental stimuli as well as overshadowing of the taste by novel environmental stimuli. Furthermore, it indicates that previous demonstrations of tastemediated environmental potentiation involve facilitated conditioning of the environmental stimuli and decremented conditioning of the taste stimuli.
\end{abstract}

Environmental stimuli can be better associated with toxicosis when a taste stimulus is present during conditioning than when it is not (Best, Brown, \& Sowell, 1984; Best, Batson, Meachum, Brown, \& Ringer, 1985). This phenomenon resembles earlier observations that odorous stimuli condition better in compound with a taste on toxicosis trials than when consumed in the absence of taste (e.g., Durlach \& Rescorla, 1980; Palmerino, Rusiniak, \& Garcia, 1980; Rusiniak, Hankins, Garcia, \& Brett, 1979). Taste can also facilitate aversive learning to the visual properties of food (Galef \& Osborne, 1978) or to the visual and/or auditory/tactile properties of fluid containers in rats (Sjöden \& Archer, 1983), to visual stimuli in various bird species (e.g., Brett, Hankins, \& Garcia, 1976; Clarke, Westbrook, \& Irwin, 1979; Lett, 1980, $1982,1984)$, and to odorous stimuli in infant rats (Kucharski \& Spear, 1985). This general phenomenon is referred to as taste-mediated potentiation.

Potentiation contrasts sharply with overshadowing. Normally, when two stimuli are reinforced in compound, conditioning is reduced to both (e.g., Mackintosh, 1971; Pavlov, 1927; Rescorla \& Wagner, 1972; Sutherland \& Mackintosh, 1971). Indeed, toxin-reinforced taste aversions are generally reduced if the target taste is experienced in successive compound with a second taste stimulus during conditioning (e.g., Cannon et al., 1985; Revusky, 1971).

Another procedure that interferes with flavor conditioning is stimulus preexposure; prior experience with a taste

We appreciate the efforts of Shari Coskey, Neil Fulbright, and Hema Patel during various stages of this project. Reprints are available from Michael Best, Department of Psychology, Southern Methodist University, Dallas, TX 75275. significantly interferes with its subsequent ability to be associated with toxicosis (e.g., for a review, see Best, 1982). Taste preexposure also reduces the ability of a taste to potentiate the conditioning of an environmental aversion (Best et al., 1985). The purpose of the present experiment was not only to look at the effects on tastemediated environmental potentiation of taste preexposure, but also to analyze the influence of preconditioning experience with the experimental environment.

To accomplish this, all animals received four conditioning sessions during which saccharin was consumed in a distinctive environment and followed by injections of lithium chloride. Prior to this conditioning sequence, various preexposure treatments were administered. Animals were preexposed to the experimental environment, to the taste, to both of these stimuli, or to neither the taste nor the environment. Animals preexposed to both the taste and the experimental environment drank saccharin during preexposure in either the home cage or the distinctive environment. The influence of these various preexposure manipulations on aversive conditioning to both the environmental and taste stimuli was then evaluated.

\section{METHOD}

\section{Subjects and Apparatus}

The subjects were 40 naive adult male Holtzman rats born and reared in the animal colony at Southern Methodist University. Five groups of 8 animals each were matched on mean weights and water consumptions prior to the start of the experiment. All animals were maintained on a 12-h-light/12-h-dark schedule from birth, were housed individually in standard Wahmann cages, and received food ad lib throughout the experiment.

Seven days prior to the first day of preexposure, all animals were adapted in a water-deprivation schedule, receiving $30 \mathrm{ml}$ of roomtemperature tap water for $10 \mathrm{~min}$ daily. Water and other fluids 
received under deprivation conditions were delivered from 50-ml polypropylene centrifuge tubes fitted with rubber stoppers and stainless steel spouts. Fluids delivered ad lib were supplied from 500 ml polypropylene bottles fitted with rubber stoppers and stainless steel spouts.

The environments used for preexposure, conditioning, and testing were polypropylene mouse breeding cages fitted with steel lids. The lids were situated such that the drinking spouts from the bottles and centrifuge tubes protruded from overhead. The cages were situated side by side on steel shelves and a work table in a dimly illuminated room immediately adjacent to the main experimental room. No food was available in these cages at any time.

\section{General Design}

The experimental design for this experiment was a modified $2 \times 3$ arrangement. All animals received identical conditioning experiences, consisting of four encounters with saccharin in the experimental environments. Lithium injections were administered immediately following the animals' removal from the experimental environments. The two dimensions along which the groups differed were their preconditioning or preexposure experience with saccharin and with the experimental environment. Along the taste dimension, animals received either no preexposure to saccharin or extensive preexposure in the home cage or in the experimental environment. Likewise, they either received extensive preexposure to the experimental environments or no preexposure to these environments. Table 1 summarizes these treatment conditions and the group labels.

\section{Procedure}

Preexposure. On Days 1-14, the animals in Group Box spent $4 \mathrm{~h}$ in the experimental environments daily. No fluid was available at this time. Following environmental exposure, all animals in this group received room-temperature tap water ad lib in the home cages for $4 \mathrm{~h}$ each day.

A second group of animals (Group SacBox) spent $4 \mathrm{~h}$ daily in the environments. At this time, each animal had available ad lib a sodium saccharin solution $(.15 \% \mathrm{w} / \mathrm{v})$. Animals in this group did not receive any type of fluid in the home cages at any time during preexposure.

Animals in Group Sac/Box were placed in the environments for $4 \mathrm{~h}$ daily without fluid. After environmental exposures, these animals received saccharin ad lib in the home cages for $4 \mathrm{~h}$.

The animals in Group Sac received saccharin ad lib in the home cages for $4 \mathrm{~h}$ daily. These animals, however, did not receive any environmental preexposure. Finally, animals in Group No Pre were given room-temperature tap water ad lib for $4 \mathrm{~h}$ daily. Like Group Sac, these animals were given no preconditioning experience with the environmental stimuli.

These preliminary preexposure manipulations were carried out beginning at $0800 \mathrm{~h}$ and ending at $1600 \mathrm{~h}$. On Days 15-28 of preexposure, all groups received manipulations identical to those administered on Days 1-14. However, the time spent in the environments for the relevant groups was reduced from $4 \mathrm{~h}$ to $30 \mathrm{~min}$. In addition, the amount of fluid delivered was reduced from 500 to $30 \mathrm{ml}$ for both water and saccharin. These preexposure manipulations were conducted at $1100 \mathrm{~h}$.

On Days 29-33, all animals were maintained on a salinedeprivation schedule, receiving $40 \mathrm{ml}$ of a $.9 \% \mathrm{w} / \mathrm{v}$ isotonic saline

Table 1

Experimental Design

\begin{tabular}{|c|c|c|}
\hline \multirow{2}{*}{$\begin{array}{c}\text { Preexposure to } \\
\text { Saccharin }\end{array}$} & \multicolumn{2}{|c|}{ Preexposure to Box } \\
\hline & No & Yes \\
\hline $\begin{array}{l}\text { None } \\
\text { Home Cage } \\
\text { Box }\end{array}$ & $\begin{array}{l}\text { No Pre } \\
\text { Sac }\end{array}$ & $\begin{array}{l}\text { Box } \\
\text { Sac/Box } \\
\text { SacBox }\end{array}$ \\
\hline
\end{tabular}

solution for $20 \mathrm{~min}$ daily. This was done to familiarize the animals with the solution used for testing and to preclude any generalization that might develop between the saccharin used for conditioning and the saline used for testing.

Conditioning. Conditioning took place on Days 34-37. The first day of conditioning, all animals were placed in the experimental environments for $20 \mathrm{~min}$ and each animal was given $7 \mathrm{ml}$ of saccharin. Immediately following environmental exposure, each animal was given a $12-\mathrm{ml} / \mathrm{kg}$ injection of .15 M lithium chloride (ip) and then returned to the home cage. Approximately $4 \mathrm{~h}$ later, all animals received their daily ration of saline in the home cages. On the remaining 3 days of conditioning, all animals received the same manipulations administered on Day 1 with a single exception: to equilibrate intakes as closely as possible across groups, the amount of saccharin delivered was reduced to $3 \mathrm{ml}$ on Days 2 and 3 and to $2 \mathrm{ml}$ on the final conditioning trial. Conditioning sessions were conducted at $1100 \mathrm{~h}$.

For 5 days between the final day of conditioning and the first day of testing, all animals received $40 \mathrm{ml}$ of saline in the home cages for $20 \mathrm{~min}$ each day.

Testing. For 3 consecutive days, all animals were placed in the conditioned environments at $1100 \mathrm{~h}$ for $20 \mathrm{~min}$. At this time, each animal received $40 \mathrm{ml}$ of saline. The animals were then removed and intakes were recorded to the nearest $0.1 \mathrm{ml}$. Approximately $4 \mathrm{~h}$ following the environmental test, each animal received in the home cage the saline it had not consumed during the environmental test. This was done to equate intakes across groups on the test days.

On 4 consecutive days after the environmental tests, all animals received saccharin for $20 \mathrm{~min}$ at $1100 \mathrm{~h}$ in their home cages. Approximately $4 \mathrm{~h}$ later, the animals received saline for $10 \mathrm{~min}$ in the home cages.

All intakes were recorded to the nearest $0.1 \mathrm{ml}$, and statistics were computed using the Mann-Whitney $U$ test for all betweengroup comparisons $(p<.05$, two-tailed).

\section{RESULTS}

\section{Preexposure}

Mean intakes across the initial 14-day, 4-h preexposure period were: Group SacBox $=26.82 \mathrm{ml}$, Group Box $=$ $31.62 \mathrm{ml}$, Group No Pre $=32.95 \mathrm{ml}$, Group Sac $=$ $40.76 \mathrm{ml}$, and Group Sac/Box $=52.47 \mathrm{ml}$. The elevated means of the latter two groups likely reflect the opportunity the animals in these groups had to consume a palatable saccharin solution in a familiar environment, the home cages. Interestingly, however, the group drinking saccharin in the experimental environment (SacBox) evidenced the lowest overall mean intake across this 14-day preexposure sequence.

During the second 14-day preexposure sequence, intakes stabilized across the groups. During this period, the animals in each group received their allotted fluid and/or environmental exposure for $30 \mathrm{~min}$ daily. The overall mean intakes across the 14 days ranged from 20.0 to $23.5 \mathrm{ml}$.

\section{Saline Intakes}

At no time in the experiment was there evidence of differential preference for the saline fluid between groups. During the daily 20-min saline exposures on the 5 days prior to conditioning, the overall mean intakes ranged from 25.9 to $30.4 \mathrm{ml}$. Likewise, on the four saline main- 
tenance periods conducted $4 \mathrm{~h}$ after each conditioning session, the overall mean intakes ranged from 23.5 to $26.5 \mathrm{ml}$. Finally, overall mean saline intakes across the 5-day period prior to environmental testing ranged from 29.66 to $34.28 \mathrm{ml}$.

\section{Conditioning}

Saccharin intakes in all groups were maintained at a relatively constant level throughout conditioning. The mean intakes in each group across the four trials ranged from 1.58 to $2.47 \mathrm{ml}$.

\section{Environmental Testing}

Table 2 displays the mean intakes for each group on the initial environmental test. As is obvious, the No Pre and Box groups consumed substantially less saline on this test than did any of the other groups. Indeed, MannWhitney $U$ tests revealed that these two groups drank significantly less than any of the other groups (highest $U=$ $11, p<.05$, two-tailed). The SacBox group also consumed significantly more saline on the test than did Groups Sac and Sac/Box (highest $U=13, p<.05$, two-tailed). None of the other comparisons was significant.

This pattern of intakes was maintained on the second environmental test. Mean intakes for the groups were: No Pre $=14.43 \mathrm{ml}$, Box $=14.35 \mathrm{ml}$, SacBox $=$ $28.83 \mathrm{ml}, \mathrm{Sac} / \mathrm{Box}=21.8 \mathrm{ml}$, and S/SB-Li $=20.84 \mathrm{ml}$. On the third test, the SacBox group drank a mean of $28.0 \mathrm{ml}$. Mean intakes in the other groups ranged from 20.6 to $23.1 \mathrm{ml}$.

\section{Saccharin Intakes}

Table 3 summarizes the mean saccharin intakes across the four postconditioning tests for each group. On all four tests, the Box group consumed less saccharin than all of the other groups (highest $U=12, p<.05$, two-tailed). In addition, the No Pre group drank significantly less saccharin on the initial two tests than did the remaining three groups (highest $U=11, p<.05$, two-tailed), each of which was familiarized with saccharin prior to condition-

Table 2

Mean Saline Consumption on Environment Test 1 (in Milliliters)

\begin{tabular}{llrl}
\hline $\begin{array}{c}\text { Preexposure to } \\
\text { Saccharin }\end{array}$ & \multicolumn{3}{c}{ Preexposure to Box } \\
\cline { 2 - 3 } None & No Pre: 6.08 & \multicolumn{1}{c}{ Yes } \\
Home Cage & Sac: & 19.40 & Sac/Box: 20.60 \\
Box & & & SacBox: 28.30 \\
\hline
\end{tabular}

Table 3

Mean Saccharin Consumption (in Milliliters) (Averaged Across the 4 Tests)

\begin{tabular}{lllr}
\hline $\begin{array}{l}\text { Preexposure to } \\
\text { Saccharin }\end{array}$ & \multicolumn{2}{c}{ Preexposure to Box } \\
\cline { 2 - 3 } & No & \multicolumn{1}{c}{ Yes } \\
\hline None & No Pre: 9.46 & Box: & 3.21 \\
Home Cage & Sac: 19.85 & Sac/Box: 14.44 \\
Box & & & SacBox: 15.21 \\
\hline
\end{tabular}

ing. Finally, the No Pre group drank significantly less saccharin than the Sac group on the third test $(U=3$, $p<.05$, two-tailed). None of the other comparisons was significant for any of the 4 saccharin test days.

\section{DISCUSSION}

Three findings from this experiment are of particular interest. First, consistent with previous observations (Best et al., 1984; Best et al., 1985), consumption of a novel taste in a distinctive environment prior to lithium-induced toxicosis potentiated aversive conditioning to the environmental stimuli. This was evidenced by the significantly diminished saline consumption in the No Pre group on the test as compared with the groups that drank familiar saccharin during environmental conditioning. It is also worth noting that the group that drank the saccharin during preexposure in the experimental environment (Group SacBox) showed the largest conditioning decrement to these noningestional stimuli among those that received saccharin preexposure. It might be argued, however, that the animals in this group-unlike those in any of the other four-had an opportunity to become accustomed to drinking in these environments during preexposure and that this experience influenced their test intakes. This argument cannot be made for the other groups that received saccharin preexposure, and it is clear that such preexposure altered significantly the ability of this taste to potentiate an environmental aversion.

In this regard, it might be argued that, since all subjects in this experiment received identical conditioning histories, it is not possible to determine unequivocally whether or not saline suppression in the No Pre group was due to taste-mediated environmental potentiation. However, a separate experiment conducted prior to the one reported here determined not only that the outcomes of the No Pre group were due to taste-mediated environmental potentiation, but also that saccharin preexposure reduces such environmental conditioning to control levels. In this experiment, one group (Sac, $n=10$ ) was treated identically to the Sac group in the present experiment; the animals were preexposed to saccharin prior to conditioning trials in which saccharin was consumed in the conditioning chamber. A second group (No Pre, $n=10$ ) was treated exactly like the No Pre group described here; the animals drank novel saccharin in the experimental environments during conditioning. The third group (Water, $n=10$ ) drank water in the environment on four occasions during conditioning. On the initial saline test in the conditioning environments 1 week later, mean intakes in the Sac Pre and Water groups were 24.73 and $20.75 \mathrm{ml}$, respectively. This was contrasted with a mean saline intake of $14.54 \mathrm{ml}$ in the No Pre group. The intakes in the No Pre group were significantly lower than those of the other two groups (lowest Mann-Whitney $U=20, p<.05$, two-tailed). On Test Day 2, saline intakes were 27.60 , 29.36 , and $17.12 \mathrm{ml}$, respectively. These data indicate that taste-mediated environmental potentiation requires the 
presence of a novel taste in the conditioning environment on lithium trials (cf. Best et al., 1985).

Of further interest was the observation that taste preexposure but not environmental preexposure interfered substantially with the development of taste-mediated environmental potentiation. Each of the groups that drank familiar saccharin in the experimental environment during conditioning consumed substantial amounts of saline on the environmental test. In contrast, the group that received only environmental preexposure prior to conditioning evidenced a pattern of potentiation only slightly higher than that in the No Pre group. The failure of environmental preexposure to interfere with taste-mediated environmental potentiation is particularly surprising considering the amount of experience these animals had with the environment prior to conditioning. Each animal was in the environment for $4 \mathrm{~h}$ daily for 2 weeks and then for 20 min daily for an additional 2 weeks. Perhaps the presence of a novel saccharin solution during conditioning served to dishabituate these stimuli (cf. Rudy, Rosenberg, \& Sandell, 1977). In any event, taste appears to play an important role in marking environmental stimuli for the control of ingestional behavior.

Another finding of interest in this experiment was revealed in the saccharin tests. The group that drank a novel saccharin taste in a novel environmental complex (Group No Pre) evidenced not only taste-mediated potentiation of these environmental stimuli, but also environment-mediated taste overshadowing. Relative to the group that drank a novel saccharin in a familiar environment (Group Box), the animals in the No Pre group demonstrated a significantly weaker saccharin aversion. This indicates that, despite the stimulus competition existing in this compound conditioning situation, potentiation can be generated. Indeed, it appears that it can be generated by a stimulus that, itself, is undergoing overshadowing. This latter finding points to the asymmetrical stimulus interactions occurring during the development of potentiation and also provides additional evidence of the primacy of taste in producing potentiation. The latter finding is similar to other observations in which taste potentiates aversions to odorous stimuli in a compound conditioning procedure under circumstances in which taste is overshadowed (e.g., Rusiniak, Palmerino, Rice, Forthman, \& Garcia, 1982; Westbrook, Homewood, Horn, \& Clarke, 1983).

Finally, the obvious reduction of environment-mediated taste overshadowing in the Box group deserves comment. Despite the substantial potentiation observed to these stimuli following the four conditioning trials in this group, these stimuli were probably perceived as familiar by the animals. Otherwise, they would likely have served as effective overshadowing stimuli, as they did in the group for which the environmental stimuli were novel at the time of conditioning (Group No Pre). For example, it has been demonstrated in other preparations that familiarity with one of the stimuli subsequently used in a compound over- shadowing procedure reduces the amount of overshadowing this stimulus exerts on a reinforced trial (e.g., Carr, 1974). In Group Box of the present experiment, a familiar environmental stimulus significantly reduced the amount of environment-mediated taste overshadowing. In contrast, the presence of novel environmental stimuli (i.e., Group No Pre) overshadowed the conditioning of the saccharin with lithium. These results indicate that familiar environmental stimuli apparently can come to suppress ingestional behavior despite their relative impotence in disrupting the development of a taste aversion.

\section{REFERENCES}

BEST, M. R. (1982). Associative and non-associative sources of interference with the acquisition of a flavor aversion. In M. L. Commons, R. J. Herrnstein, \& A. R. Wagner (Eds.), Quantitative analyses of behavior: Vol. 3. Acquisition. Cambridge, MA: Ballinger.

Best, M. R., Brown, E. R., \& Sowell, M. K. (1984). Taste-mediated potentiation of noningestional stimuli in rats. Learning \& Motivation, 15, 244-258.

Best, M. R., Batson, J. D., Meachum, C. L., Brown, E. R., \& RINGER, M. (1985). Characteristics of taste-mediated environmental potentiation in rats. Learning \& Motivation, 16, 190-209.

Brett, L. P., Hankins, W. G., \& Garcia, J. (1976). Prey-lithium aversions. III: Buteo hawks. Behavioral Biology, 17, 87-98.

Cannon, D. S., Best, M. R., Batson, J. D., Brown, E. R., RubenStein, J. A., \& Carrell, L. E. (1985). Interfering with taste aversion learning in rats: The role of associative interference. Appetite, 6, 1-19.

CARR, A. F. (1974). Latent inhibition and overshadowing in conditioned emotional response conditioning with rats. Journal of Comparative \& Physiological Psychology, 86, 718-723.

Clark, J. C., Westbrook, R. F., \& IRwin, J. (1979). Potentiation instead of overshadowing in the pigeon. Behavioral \& Neural Biology, 25, 18-29.

Durlach, R. J., \& Rescorla, R. A. (1980). Potentiation rather than overshadowing in flavor-aversion learning: An analysis in terms of within-compound associations. Journal of Experimental Psychology: Animal Behavior Processes, 6, 175-187.

Galef, B. G., \& Osborne, B. (1978). Novel taste facilitation of the association of visual cues with toxicosis in rats. Journal of Comparative \& Physiological Psychology, 92, 907-916.

KuchaRSKI, D., \& SpEar, N. E. (1985). Potentiation and overshadowing in preweanling and adult rats. Journal of Experimental Psychology, 11, 15-34.

LETT, B. T. (1980). Taste potentiates color-sickness associations in pigeons and quail. Animal Learning \& Behavior, 8, 193-198.

LETT, B. T. (1982). Taste potentiation in poison avoidance learning. In M. L. Commons, R. J. Herrnstein, \& A. R. Wagner (Eds.), Quantitative analyses of behavior: Vol 3. Acquisition. Cambridge, MA: Ballinger.

LETT, B. T. (1984). Extinction of taste aversion does not eliminate taste potentiation of odor aversion in rats or color aversion in pigeons. Animal Learning \& Behavior, 12, 414-420.

Mackintosh, N. J. (1971). An analysis of overshadowing and blocking. Quarterly Journal of Experimental Psychology, 23, 118-125.

Palmerino, C. C., Rusiniak, K. W., \& Garcia, J. (1980). Flavorillness aversions: The peculiar roles of odor and taste in memory for poison. Science, 208, 753-755.

Pavlov, I. P. (1927). Conditioned reflexes (G. V. Anrep, Trans.). London: Oxford University Press.

Rescorla, R. A., \& WAGner, A. R. (1972). A theory of Pavlovian conditioning: Variations in the associability of stimuli with reinforcement. In A. Black \& W. F. Prokasy (Eds.), Classical conditioning: II. Current theory and research. New York: Appleton-Century-Crofts. REvusky, S. (1971). The role of interference in association over a de- 
lay. In W. K. Honig \& P. H. R. James (Eds.), Animal memory. New York: Academic Press.

Rudy, J. W., Rosenaerg, L., \& Sandell, J. H. (1977). Disruption of a taste familiarity effect by novel exteroceptive stimulation. Journal of Experimental Psychology, 3, 26-36.

Rusiniak, K. W., Hankins, W. G., Garcia, J., \& Brett, L. P. (1979). Flavor-illness aversions: Potentiation of odor by taste in rats. $\mathrm{Be}$ havioral \& Neural Biology, 25, 1-17.

Rusiniak, K. W., Palmerino, C. C., Rice, A. G., Forthman, D. L., \& GarCIA, J. (1982). Flavor-illness aversions: Potentiation of odor by taste with toxin but not shock in rats. Journal of Comparative \& Physiological Psychology, 96, 527-539.
SJöden, P., \& ARCher, T. (1983). Potentiation of a bottle aversion in compound conditioning with rats. Experimental Animal Behavior, 2, $1-18$.

Sutherland, N. S., \& Mackintosh, N. J. (1971). Mechanisms of animal discrimination learning. New York: Academic Press.

Westbrook, R. F., Homewood, J., Horn, K., \& Clarke, J. C. (1983). Flavour-adour compound conditioning: Odour potentiation and flavour attenuation. Quarterly Journal of Expenimental Psychology, 35B, 13-33.

(Manuscript received May 30, 1985; revision accepted for publjcation January 27,1986 .) 